\title{
MATÉRIA SECA E ALTURA DAS PLANTAS DE SOJA E ARROZ EM FUNÇÃO DO GRAU DE COMPACTAÇÃO E DO TEOR DE ÁGUA DE DOIS LATOSSOLOS ${ }^{1}$
}

\begin{abstract}
AMAURI N. BEUTLER ${ }^{2}$, JOSÉ F. CENTURION ${ }^{3}$
RESUMO: Este trabalho teve o objetivo de avaliar a altura de plantas e a produção de matéria seca da parte aérea e das raízes de soja e arroz em dois teores de água (água retida a 0,05 e a $0,01 \mathrm{MPa}$ ) e três de resistência do solo à penetração (entre 0,25 e 6,46 MPa), determinados com o penetrômetro de anel dinamométrico. Foram utilizadas amostras de Latossolo Vermelho, distrófico, textura média (LVd) e Latossolo Vermelho, eutroférrico, textura argilosa (LVef), coletadas na profundidade de 0,0-0,20 m e compactadas em camadas de $0,03 \mathrm{~m}$, em vasos de $0,20 \mathrm{~m}$ de altura e $0,25 \mathrm{~m}$ de diâmetro. A altura das plantas foi reduzida para valores de resistência à penetração superiores a 3,0 MPa. A menor produção de matéria seca da parte aérea das plantas ocorreu na resistência à penetração de 3,76 e 3,37 MPa para soja; 3,93 e 3,37 MPa para arroz, no Latossolo Vermelho, textura média e Latossolo Vermelho argiloso, respectivamente, no teor de água retida na tensão de $0,05 \mathrm{MPa}$, e no maior teor de água somente ocorreu redução da produção de matéria seca das raízes.
\end{abstract}

PALAVRAS-CHAVE: matéria seca, Glycine max, Oryza sativa.

\section{HEIGHT AND DRY MATTER OF SOYBEAN AND RICE IN FUNCTION OF DEGREE OF COMPACTION AND WATER CONTENT OF TWO OXISOLS}

SUMMARY: This research was carried out to evaluate the height of plants and production of aerial and root dry matter of soybean and rice in two water contents (water content at tension 0.05 and $0.01 \mathrm{MPa}$ ) and three levels of resistance to penetration (between 0.25 and $6.46 \mathrm{MPa}$ ) determined with penetrometer dinamometric ring. Samples of Haplustox and Eutrustox, medium and clayey texture were collected in depth of 0.0-0.20 m and compact in layers of $0.03 \mathrm{~m}$ in pots of $0.20 \mathrm{~m}$ of height and $0.25 \mathrm{~m}$ of diameter. The height of plants was reduced in values of penetration resistance greater of 3.0 MPa. The smaller production of aerial part dry matter of the plants occurred in penetration resistance of 3.76 and $3.37 \mathrm{MPa}$ for soybean; 3.93 and $3.37 \mathrm{MPa}$ for rice, in Haplustox and Eutrustox, respectively, in the water content in tension of $0.05 \mathrm{MPa}$, and in the greater water content only occurred reduction of root dry matter.

KEYWORDS: dry matter, Glycine max, Oryza sativa

\footnotetext{
${ }^{1}$ Parte da tese de doutorado do primeiro autor. Projeto financiado pela Fapesp.

${ }^{2}$ Doutor em Produção Vegetal, FCAV/UNESP, Jaboticabal - SP, e-mail: amaurib@yahoo.com.br. Bolsista da Fapesp.

${ }^{3}$ Prof. Adjunto, Departamento de Solos e Adubos, FCAV/UNESP, Jaboticabal - SP, e-mail:

jfcentur@fcav.unesp.br

Recebido pelo Conselho Editorial em: 29-10-2002

Aprovado pelo Conselho Editorial em: 5-11-2003
}

Eng. Agric., Jaboticabal, v.24, n.1, p.142-149, jan./abr. 2004 


\section{INTRODUÇÃO}

A compactação do solo, originada da pressão exercida pelos pneus das máquinas e por implementos agrícolas sobre o solo, principalmente em condições de excesso de água no solo, é um dos principais problemas físicos que limitam a produtividade de soja e arroz de sequeiro.

A compactação do solo, genericamente caracterizada pela diminuição do volume de vazios ocupados pela água ou pelo ar, limita a infiltração e a redistribuição de água no solo; reduz as trocas gasosas e a disponibilidade de oxigênio, que afeta o crescimento das raízes em busca de água e nutrientes; limita o crescimento radicular por impedimento mecânico, culminando com a redução do crescimento da parte aérea e da produtividade das culturas (BELTRAME \& TAYLOR, 1980).

Em solos compactados, ocorrem mudanças e redução no comprimento do sistema radicular, restringindo a absorção de água e nutrientes, não necessariamente refletindo em redução do crescimento da parte aérea, pois, muitas vezes, o sistema radicular é reduzido e mantém satisfatoriamente o suprimento de água e nutrientes à parte aérea (TAYLOR \& BRAR, 1991). Por outro lado, solos muito porosos podem não afetar o crescimento radicular, porém o menor contato do solo com a raiz pode diminuir a absorção de água e nutrientes. Estudos mostram que uma pequena compactação é benéfica por aumentar a área de contato entre o solo e a raiz (SIDIRAS \& VIEIRA, 1984; KOOISTRA et al., 1992). Esses autores afirmaram que uma pequena compactação pode proporcionar melhor retenção de água e melhores condições de absorção de nutrientes por unidade de raiz. CINTRA \& MIELNICZUK (1983) observaram que a cultura de soja e trigo responderam positivamente ao incremento da compactação até a densidade de $1,04 \mathrm{Mg} \mathrm{m}^{-3}$. A estrutura ideal ao crescimento das plantas, segundo KOPI \& DOUGLAS (1991), está relacionada a uma grande área de contato entre o solo e a raiz, espaço poroso suficiente para o movimento de água e gases e baixa resistência do solo à penetração das raízes.

A tolerância das plantas à compactação do solo está diretamente relacionada ao teor de água do mesmo, conforme verificado por STIRZAKER et al. (1996) e RIBEIRO (1999), que verificaram que, em maiores teores de água, o valor de resistência que impediu o crescimento radicular, é superior em relação a solos mais secos. Esses autores verificaram que, em solos com maior teor de água, o crescimento de cevada foi maior na densidade intermediária e, em menor teor de água, o crescimento foi superior no menor nível de compactação.

Para estudos de compactação do solo, a resistência do solo à penetração é a propriedade mais avaliada atualmente, por estar diretamente relacionada com o crescimento das plantas e por ser de fácil e rápida determinação (WEAICH et al., 1992). Valores de resistência do solo à penetração restritivos ao crescimento radicular variam de 1 a 4 MPa (NESMITH, 1987; GRANT \& LAFOND, 1993; TOPP et al., 1994; ARSHAD et al., 1996), sendo, em geral, o valor de 2,0 MPa aceito como impeditivo ao crescimento radicular (TORMENA et al., 1998), apesar de as diferentes espécies apresentarem competências diferenciadas para penetrar o solo.

MIELNICZUK et al. (1985) verificaram em Latossolo Roxo compactado artificialmente (teor de água de $0,28 \mathrm{~kg} \mathrm{~kg}^{-1}$ ), que a produção de matéria seca de soja, trigo e aveia foram menores a partir da resistência à penetração de 3,13 MPa. Em condições de campo, SECCO et al. (2000), em Latossolo Vermelho, com resistência à penetração de 2,0 a 2,4 MPa, verificaram redução de 8,3\% na produção de trigo. PETTER (1990) verificou menor crescimento radicular de soja a partir de 2,8 $\mathrm{MPa}$, em condições de campo. 
$\mathrm{Na}$ literatura, encontram-se alguns estudos avaliando a influência de camadas subsuperficias de solo compactadas na produção de matéria seca pelas culturas. Entretanto, há necessidade de estudos em sistemas com revolvimento mínimo do solo, como o plantio direto, que promovem a formação de camadas compactadas na profundidade de 0,07 a 0,17 m (SILVA et al., 2000).

Este estudo teve por objetivo avaliar a altura de plantas e matéria seca da parte aérea e das raízes de soja e arroz em níveis de resistência à penetração e teores de água de Latossolo Vermelho, distrófico, textura média e Latossolo Vermelho, eutroférrico, textura argilosa.

\section{MATERIAL E MÉTODOS}

O experimento foi realizado em casa de vegetação do Departamento de Solos e Adubos da FCAV/UNESP de Jaboticabal - SP, em Latossolo Vermelho, distrófico, típico, textura média, A moderado, caulinítico, hipoférrico (LVd) e Latossolo Vermelho, eutroférrico, típico, textura argilosa, A moderado, caulinítico-oxídico (LVef). Os solos LVd e LVef apresentaram, respectivamente, 271 e $517 \mathrm{~g} \mathrm{~kg}^{-1}$ de argila, 42 e $256 \mathrm{~g} \mathrm{~kg}^{-1}$ de silte e 687 e $227 \mathrm{~g} \mathrm{~kg}^{-1}$ de areia.

As amostras dos solos foram coletadas na camada de 0,0-0,20 m e passadas em peneira de 0,004 m (MORAES et al., 1991). O solo utilizado para cada cultura foi adubado segundo RAIJ et al. (1996), cuja análise química seguiu a metodologia de RAIJ et al. (1987).

Após a realização da adubação, foram ajustados os teores de água equivalente ao teor de água retida nas tensões de 0,05 e $0,01 \mathrm{MPa}$, determinada previamente em amostras deformadas, segundo KLUTE (1986). Em seguida, mantendo o solo sempre coberto para evitar perda de água, o mesmo foi colocado em vaso cilíndrico de PVC com capacidade de 9,82 L (altura de 0,20 m e diâmetro de $0,25 \mathrm{~m}$ ), em camadas de $0,03 \mathrm{~m}$. Cada camada foi compactada por meio da queda livre de um êmbolo de $7 \mathrm{~kg}$, da altura de $0,60 \mathrm{~m}$, no centro geométrico de um suporte de madeira com diâmetro ligeiramente inferior ao do vaso, semelhante ao descrito por MORAES et al. (1991).

Os níveis de resistência do solo à penetração (RP) foram obtidos por meio da aplicação de $0 ; 5$; 11 e $0 ; 7 ; 13$ impactos por camada de solo, para o LVd e LVef, respectivamente. No LVef, foi necessário maior número de impactos por camada para obter valor semelhante de RP em relação ao LVd devido a sua microestrutura, que o torna mais resistente à compactação.

A RP foi determinada com o penetrômetro de anel dinamométrico (Solotest 1.210.001), com ângulo de cone de $30^{\circ}$ recomendado pela ASAE (1976). As leituras foram realizadas quando a base do cone atingiu a profundidade de $0,03 \mathrm{~m}$, sendo o valor de cada repetição obtido da média de quatro subdeterminações. Utilizou-se de cone com diâmetro de 0,$0284 ; 0,022$ e $0,012 \mathrm{~m}$, respectivamente, diminuindo o diâmetro do cone com o incremento da RP. O valor obtido no aparelho foi transformado em kgf pela equação linear de calibração, a seguir:

$$
\mathrm{R}(\mathrm{kgf})=1,0444+0,2998 \mathrm{x}
$$

em que,

$\mathrm{R}(\mathrm{kgf})$ - resistência à penetração $((\mathrm{kgf} /$ área cone $) \times 0,098=\mathrm{MPa}), \mathrm{e}$

$\mathrm{x}$ - leitura do aparelho.

Foram colocadas três sementes de soja (Glycine max $c v$. EMBRAPA 48) por cova (quatro covas por vaso) e arroz (Oryza sativa cv. IAC 165), no ano de 2000. Após sete dias, realizou-se o desbaste, deixando duas plantas de soja e quatro plantas de arroz por vaso, respectivamente. Nessa data, foram aplicados os tratamentos de teores de água, visto que foi necessário aumentar o teor de água do solo para possibilitar a germinação nos vasos mais secos e compactados. $\mathrm{O}$ teor de água foi mantido constante, por meio de pesagem diária dos vasos referentes a uma repetição e reposição de água por 
meio de tubo de PVC perfurado, instalado no centro geométrico do vaso, sendo feita a pesagem e o rodízio de todos os vasos a cada cinco dias.

No início do florescimento, aos 54 dias após a semeadura, foram avaliadas a altura das plantas e a matéria seca da parte aérea e das raízes das plantas de soja e arroz. Para a avaliação da matéria seca da parte aérea, as plantas foram secionadas na altura da superfície do solo e, para a matéria seca das raízes, as mesmas foram separadas do solo por lavagem em água corrente. Em seguida, a parte aérea e as raízes foram secas em estufa $\mathrm{a} \pm 60^{\circ} \mathrm{C}$ até atingir peso constante.

Os tratamentos consistiram de três níveis de RP e dois teores de água para cada cultura e solo, constituindo um experimento inteiramente casualizado, em esquema fatorial 3 x 2, com três repetições. A análise estatística dos resultados consistiu da análise da variância e utilização do teste de Tukey, a $5 \%$ de probabilidade para a comparação das médias.

\section{RESULTADOS E DISCUSSÃO}

\section{Altura e matéria seca das plantas de soja}

A altura das plantas de soja foi superior no maior teor de água, no LVd e LVef, condizente com a maior disponibilidade de água (Tabela 1).

TABELA 1. Altura média de plantas de soja $(n=3)$ aos 54 dias após a semeadura, no LVd e LVef, em três níveis de resistência à penetração $(\mathrm{RP})$ e dois teores de água.

\begin{tabular}{|c|c|c|c|c|c|c|c|}
\hline \multicolumn{4}{|c|}{ LVd } & \multicolumn{4}{|c|}{ LVef } \\
\hline \multicolumn{4}{|c|}{ Teor de Água $\left(\mathrm{kg} \mathrm{kg}^{-1}\right)$} & \multicolumn{4}{|c|}{ Teor de Água $\left(\mathrm{kg} \mathrm{kg}^{-1}\right)$} \\
\hline 0,12 & 0,17 & 0,12 & 0,17 & 0,20 & 0,26 & 0,20 & 0,26 \\
\hline \multicolumn{2}{|c|}{$\mathrm{RP}(\mathrm{MPa})$} & \multicolumn{2}{|c|}{ Altura $(\mathrm{cm})$} & \multicolumn{2}{|c|}{$\mathrm{RP}(\mathrm{MPa})$} & \multicolumn{2}{|c|}{ Altura (cm) } \\
\hline 0,38 & 0,27 & $74,4 \mathrm{Ba}$ & $96,8 \mathrm{Aa}$ & 0,64 & 0,36 & $53,8 \mathrm{Ba}$ & $73,0 \mathrm{Aa}$ \\
\hline 1,95 & 1,79 & $72,2 \mathrm{Ba}$ & $96,2 \mathrm{Aa}$ & 3,37 & 2,03 & $31,9 \mathrm{Bb}$ & $79,4 \mathrm{Aa}$ \\
\hline 3,76 & 2,69 & $62,1 \mathrm{Ba}$ & $95,8 \mathrm{Aa}$ & 5,84 & 3,76 & $27,7 \mathrm{Bb}$ & $75,0 \mathrm{Aa}$ \\
\hline
\end{tabular}

Médias não seguidas pela mesma letra maiúscula na linha e minúscula na coluna diferem entre si, pelo teste de Tukey, a $5 \%$ de probabilidade.

A altura média das plantas não diferiu entre os níveis de RP, no LVd. Já no LVef, no menor teor de água, ocorreu redução da altura de plantas a partir da RP de 3,37 MPa, fato não verificado na RP de 0,36 a 3,76 MPa no maior teor de água, corroborando o de STIRZAKER et al. (1996) e RIBEIRO (1999). Isso deve-se ao menor teor de água no solo que, possivelmente, levou à deficiência de água e nutrientes, resultando em menor crescimento da parte aérea das plantas. Nesse contexto, TARDIEU (1994) verificou que, em solos compactados, ocorre rápida depleção de água nos poros ocupados pelas raízes, que aumenta a resistência lateral à penetração das raízes e aumenta a resistência ao fluxo de água em direção às raízes.

No menor teor de água no LVd, a RP de 3,76 MPa não afetou a altura das plantas, enquanto a RP de 3,37 $\mathrm{MPa}$, no LVef, restringiu a altura das plantas. Esse resultado deve-se, provavelmente, à utilização do teor de água retido à maior tensão no LVef em relação ao LVd, corroborando o de RIBEIRO (1999), que verificou que a compactação do solo é mais prejudicial ao crescimento das plantas de soja em solo argiloso e com menor teor de água, em relação ao solo arenoso.

$\mathrm{O}$ teor de água determinado em amostras deformadas, na tensão de 0,05 e 0,01 MPa, diferiu em relação ao teor de água determinado em amostras indeformadas de 0,11 e 0,$14 ; 0,24$ e $0,27 \mathrm{~kg} \mathrm{~kg}^{-1}$, para o LVd e LVef, na tensão de 0,05 e $0,01 \mathrm{MPa}$, respectivamente. SIDIRAS et al. (1984) afirmam que amostras indeformadas estimam melhor a realidade e as condições de campo. 
A produção de matéria seca da parte aérea e das raízes de soja foi superior no maior teor de água, no LVd e LVef (Tabela 2). No maior teor de água, a matéria seca da parte aérea aumentou na RP de 1,79 e não diferiu de 2,69 $\mathrm{MPa}$, e a matéria seca das raízes foi superior na RP de 1,79 $\mathrm{MPa}$, no LVd. Segundo SIDIRAS \& VIEIRA (1984), isso possivelmente está relacionado ao maior contato do solo com a raiz, que proporciona maior absorção de água e nutrientes por unidade de raiz. Maior produção de matéria seca com uma pequena compactação também foi verificada por CINTRA \& MIELNICZUCK (1983) em soja e trigo, e STIRZAKER et al. (1996) em cevada.

TABELA 2. Peso médio de matéria seca da parte aérea e das raízes das plantas de soja $(\mathrm{n}=3)$, no LVd e LVef, em três níveis de resistência à penetração (MPa) e dois teores de água.

\begin{tabular}{|c|c|c|c|c|c|}
\hline \multicolumn{6}{|c|}{ LVd } \\
\hline \multicolumn{6}{|c|}{ Teor de Água, $\mathrm{kg} \mathrm{kg}^{-1}$} \\
\hline 0,12 & 0,17 & 0,12 & 0,17 & 0,12 & 0,17 \\
\hline \multirow{2}{*}{\multicolumn{2}{|c|}{$\begin{array}{l}\text { Resistência à } \\
\text { Penetração }\end{array}$}} & \multicolumn{4}{|c|}{ Matéria seca $(\mathrm{g})$} \\
\hline & & \multicolumn{2}{|c|}{ Parte Aérea } & \multicolumn{2}{|c|}{ Raízes } \\
\hline 0,38 & 0,27 & $8,1 \mathrm{Ba}$ & $12,1 \mathrm{Ab}$ & $2,6 \mathrm{Ba}$ & $3,9 \mathrm{Ab}$ \\
\hline 1,95 & 1,79 & $8,7 \mathrm{Ba}$ & $17,9 \mathrm{Aa}$ & $2,1 \mathrm{Ba}$ & 4,4 Aa \\
\hline 3,76 & 2,69 & $4,6 \mathrm{Bb}$ & $15,0 \mathrm{Aab}$ & $0,9 \mathrm{Bb}$ & $4,0 \mathrm{Ab}$ \\
\hline \multicolumn{6}{|c|}{ LVef } \\
\hline \multicolumn{6}{|c|}{ Teor de Água $\left(\mathrm{kg} \mathrm{kg}^{-1}\right)$} \\
\hline 0,20 & 0,26 & 0,20 & 0,26 & 0,20 & 0,26 \\
\hline 0,64 & 0,36 & $4,9 \mathrm{Ba}$ & $10,6 \mathrm{Ab}$ & $2,0 \mathrm{Ba}$ & $4,8 \mathrm{Aa}$ \\
\hline 3,37 & 2,03 & $1,9 \mathrm{Bb}$ & $17,1 \mathrm{Aa}$ & $0,4 \mathrm{Bb}$ & $3,5 \mathrm{Ab}$ \\
\hline 5,84 & 3,76 & $1,9 \mathrm{Bb}$ & $17,5 \mathrm{Aa}$ & $0,5 \mathrm{Bb}$ & $3,6 \mathrm{Ab}$ \\
\hline
\end{tabular}

Médias não seguidas pela mesma letra maiúscula na linha e minúscula na coluna diferem entre si, pelo teste de Tukey, a $5 \%$ de probabilidade.

No maior teor de água, no LVef, a matéria seca da parte aérea aumentou e a das raízes diminuiu na RP de 2,03 MPa e não diferiu de 3,76 MPa, corroborando os de MIELNICZUK et al. (1985) e TAYLOR \& BRAR (1991). Esses autores afirmam que, muitas vezes, o sistema radicular é reduzido, porém, mantém satisfatoriamente o suprimento de água e nutrientes à parte aérea. MIELNICZUK et al. (1985), em experimento semelhante, em Latossolo Roxo, verificaram menor produção de matéria seca da parte aérea de soja aos 57 dias, na $\mathrm{RP}$ de 3,13 $\mathrm{MPa}$, em relação à $\mathrm{RP}$ de 0,19 e 2,35 $\mathrm{MPa}$, no teor de água de $0,28 \mathrm{~kg} \mathrm{~kg}^{-1}$.

No menor teor de água, ocorreu redução da matéria seca da parte aérea e das raízes de soja, na $\mathrm{RP}$ de 3,76 e 3,37 MPa, no LVd e no LVef, respectivamente. Esses resultados corroboram os de STIRZAKER et al. (1996), que verificaram que, em menores teores de água, menores níveis de compactação proporcionam melhores respostas. No menor teor de água, o valor de RP restritivo à produção de matéria seca da parte aérea de soja, no LVef, foi menor em relação ao LVd. Isso é atribuído à utilização do teor de água retido em maior tensão, no LVef, resultando em menor teor de água disponível às plantas, comparado ao LVd.

\section{Altura e matéria seca das plantas de arroz}

A altura das plantas de arroz, no maior teor de água, foi superior na RP de 1,79 e 2,83 MPa, no LVd (Tabela 3). No LVef, na RP de 1,91 e 3,53 MPa, ocorreu maior altura de plantas em relação ao menor valor RP, corroborando os estudos de CINTRA \& MIELNICZUCK (1983) e STIRZAKER et al. (1996), bem como os de SIDIRAS \& VIEIRA (1984), afirmando que pequena compactação do solo melhora a retenção de água e proporciona maior absorção de água e nutrientes por unidade de raiz. 
No menor teor de água, no LVd, a altura das plantas de arroz foi superior em solo de RP de 1,99 MPa, apresentando valores inferiores na RP de 3,93 MPa. Já no Lvef, ocorreu redução da altura de plantas a partir de 3,37 $\mathrm{MPa}$.

TABELA 3. Altura média de plantas de arroz $(n=3)$ aos 54 dias após a semeadura, no LVd e LVef, em três níveis de resistência à penetração $(\mathrm{RP})$ e dois teores de água.

\begin{tabular}{|c|c|c|c|c|c|c|c|}
\hline \multicolumn{4}{|c|}{$\mathrm{LVd}$} & \multicolumn{4}{|c|}{ LVef } \\
\hline \multicolumn{4}{|c|}{ Teor de Água $\left(\mathrm{kg} \mathrm{kg}^{-1}\right)$} & \multicolumn{4}{|c|}{ Teor de Água $\left(\mathrm{kg} \mathrm{kg}^{-1}\right)$} \\
\hline 0,12 & 0,17 & 0,12 & 0,17 & 0,20 & 0,28 & 0,20 & 0,28 \\
\hline \multicolumn{2}{|c|}{ RP (MPa) } & \multicolumn{2}{|c|}{ Altura $(\mathrm{cm})$} & \multicolumn{2}{|c|}{$\mathrm{RP}(\mathrm{MPa})$} & \multicolumn{2}{|c|}{ Altura $(\mathrm{cm})$} \\
\hline 0,42 & 0,25 & $19,5 \mathrm{Ab}$ & $19,7 \mathrm{Ab}$ & 0,57 & 0,40 & $14,8 \mathrm{Ba}$ & $18,4 \mathrm{Ab}$ \\
\hline 1,99 & 1,79 & $26,1 \mathrm{Ba}$ & $28,3 \mathrm{Aa}$ & 3,37 & 1,91 & $7,0 \mathrm{Bb}$ & $27,5 \mathrm{Aa}$ \\
\hline 3,93 & 2,83 & $21,3 \mathrm{Bb}$ & $27,3 \mathrm{Aa}$ & 6,46 & 3,53 & $6,0 \mathrm{Bb}$ & $29,4 \mathrm{Aa}$ \\
\hline
\end{tabular}

Médias não seguidas pela mesma letra maiúscula na linha e minúscula na coluna diferem entre si, pelo teste de Tukey, a $5 \%$ de probabilidade.

A altura de plantas na menor RP não foi influenciada pelo teor de água até 54 dias após a semeadura, no LVd. Isso deve-se, possivelmente, ao menor contato do solo com a raiz, reduzindo a absorção de nutrientes, conforme mencionado por KOOISTRA et al. (1992). No LVef, a altura de plantas foi superior no maior teor de água.

A produção de matéria seca da parte aérea e das raízes de arroz foi superior no segundo e terceiro níveis de RP, nos dois solos, no maior teor de água (Tabela 4), o que é corroborado por KOOISTRA et al. (1992).

TABELA 4. Peso médio de matéria seca da parte aérea e das raízes das plantas de arroz $(\mathrm{n}=3)$, no LVd e LVef, em três níveis de resistência à penetração (MPa) e dois teores de água.

\begin{tabular}{|c|c|c|c|c|c|}
\hline \multicolumn{6}{|c|}{$\mathrm{LVd}$} \\
\hline \multicolumn{6}{|c|}{ Teor de Água $\left(\mathrm{kg} \mathrm{kg}^{-1}\right)$} \\
\hline 0,12 & 0,17 & 0,12 & 0,17 & 0,12 & 0,17 \\
\hline \multirow{2}{*}{\multicolumn{2}{|c|}{$\begin{array}{l}\text { Resistência à } \\
\text { Penetração }\end{array}$}} & \multicolumn{4}{|c|}{ Matéria Seca $(\mathrm{g})$} \\
\hline & & \multicolumn{2}{|c|}{ Parte aérea } & \multicolumn{2}{|c|}{ Raízes } \\
\hline 0,42 & 0,25 & $3,8 \mathrm{Ab}$ & $4,2 \mathrm{Ab}$ & $2,2 \mathrm{Ba}$ & $3,5 \mathrm{Ab}$ \\
\hline 1,99 & 1,79 & 7,6 $\mathrm{Ba}$ & $12,7 \mathrm{Aa}$ & $2,1 \mathrm{Ba}$ & 4,6 Aa \\
\hline 3,93 & 2,83 & $4,0 \mathrm{Bb}$ & $12,2 \mathrm{Aa}$ & $1,3 \mathrm{Bb}$ & $4,0 \mathrm{Aab}$ \\
\hline \multicolumn{6}{|c|}{ LVef } \\
\hline \multicolumn{6}{|c|}{ Teor de Água $\left(\mathrm{kg} \mathrm{kg}^{-1}\right)$} \\
\hline 0,20 & 0,28 & 0,20 & 0,28 & 0,20 & 0,28 \\
\hline 0,57 & 0,40 & $2,1 \mathrm{Ba}$ & $5,6 \mathrm{Ac}$ & $0,4 \mathrm{Ba}$ & $0,8 \mathrm{Ab}$ \\
\hline 3,37 & 1,91 & $0,2 \mathrm{Bb}$ & $10,2 \mathrm{Ab}$ & $0,1 \mathrm{Bb}$ & 2,9 Aa \\
\hline 6,46 & 3,53 & $0,1 \mathrm{Bb}$ & $12,5 \mathrm{Aa}$ & $0,1 \mathrm{Bb}$ & $3,2 \mathrm{Aa}$ \\
\hline
\end{tabular}

Médias não seguidas pela mesma letra maiúscula na linha e minúscula na coluna diferem entre si, pelo teste de Tukey, a $5 \%$ de probabilidade.

No menor teor de água, no $\mathrm{LVd}$, a matéria seca da parte aérea e das raízes aumentou até a RP de 1,99 MPa, apresentando valores inferiores na RP de 3,93 MPa. Já no LVef, ocorreu a senescência das plantas na RP de 3,37 MPa, quando foram aplicados os tratamentos de teores de água. 
A menor tolerância das plantas de arroz, assim como de soja, no menor teor de água, no LVef, em relação ao $\mathrm{LVd}$, deve-se principalmente ao teor de água utilizado no experimento ser o teor retido em maiores tensões em relação ao $\mathrm{LVd}$, resultando em menor teor de água disponível às plantas.

A RP de 2,0 MPa, considerada impeditiva ao crescimento radicular, não restringiu a produção de matéria seca das raízes e da parte aérea das plantas de soja e arroz no teor de água retida na tensão de $0,01 \mathrm{MPa}$, sendo no menor teor de água que as plantas foram mais sensíveis à RP.

\section{CONCLUSÕES}

A altura das plantas foi reduzida em valores de RP superiores a 3,00 MPa. A produção de matéria seca da parte aérea das plantas foi reduzida na RP de 3,76 e 3,37 MPa para soja, no menor teor de água no solo; 3,93 e 3,37 MPa para arroz, no Latossolo Vermelho, textura média e Latossolo Vermelho argiloso, respectivamente, no teor de água retido na tensão de $0,05 \mathrm{MPa}$. No maior teor de água, ocorreu redução da produção de matéria seca das raízes apenas da soja.

\section{REFERÊNCIAS BIBLIOGRÁFICAS}

AMERICAN SOCIETY OF AGRICULTURAL ENGINEERS. Soil cone penetrometer. In: ASAE. Agricultural Engineers Yearbook. St. Joseph, 1976. p.368-9 (ASAE Rec., 313.1).

ARSHAD, M.A.; LOWERY, B.; GROSSMAN, B. Physical tests for monitoring soil quality. In: DORAN, J.W.; JONES, A.J. (Ed.) Methods for assessing soil quality. Madison: Soil Science Society of America, 1996. p.123-41 (SSSA Special Publication n.49).

BELTRAME, L.F.S.; TAYLOR, J.C. Causas e efeitos da compactação do solo. Lavoura Arrozeira, Porto Alegre, p.59-62, 1980.

CINTRA, F.L.D.; MIELNICZUK, J. Potencial de algumas espécies vegetais para recuperação de solos com propriedades físicas degradadas. Revista Brasileira de Ciência do Solo, Campinas, v.7, p.323-7, 1983.

GRANT, C.A.; LAFOND, G.P. The effects of tillage systems and crop sequences on soil bulk density and penetration resistance on a clay soil in southern Saskatchewan. Canadian Journal of Soil Science, Ottawa, v.73, p.223-32, 1993.

KLUTE, A. Water retention: laboratory methods. In: KLUTE, A. (Ed.) Methods of soil analysis. 2. ed. Madison: American Society of Agronomy, 1986. Part 1, p.635-62.

KOOISTRA, M.J.; SCHOONDERBEEK, D.; BOONE, F.R.; VEEN, B.W.; NOORDWIJK, M van. Root-soil contact of maize, as measured by a thin-section technique. II. Effects of soil compaction. Plant and Soil, Dordrecht, v.139, p.119-29, 1992.

KOPI, A.J.; DOUGLAS, J.T. A rapid inexpensive and quantitative procedure for assessing soil structure with respect to cropping. Soil Use and Management, Oxford, v.7, p.52-6, 1991.

MIELNICZUK, J.; CARPENEDO, V.; PEDO, F. Desenvolvimento de raízes em solos compactados. Lavoura Arrozeira, Porto Alegre, v.38, p.42-3, 1985.

MORAES, M.H.; BENEZ, S.H.; LIBARDI, P.L. Influência de camadas compactadas de subsuperfície no desenvolvimento do sistema radicular de plantas de soja (Glycine max (L) Merrill). Científica, São Paulo, v.19, p.195-206, 1991.

NESMITH, D.S. Soil compaction in double cropped wheat and soyabean on Ultissol. Soil Science Society of America Journal, Madison, v.51, p.183-6, 1987. 
PETTER, R.L. Desenvolvimento radicular da soja em função da compactação do solo, conteúdo de água e fertilidade em Latossolo. 1990. 144 f. Dissertação (Mestrado em Biodinâmica do Solo) Universidade Federal de Santa Maria, Santa Maria, 1990.

RAIJ, B. van; CANTARELLA, H.; QUAGGIO, J.H.; FURLANI, A.M.C. Recomendação de adubação e calagem para o Estado de São Paulo. 2. ed. Campinas: Instituto Agronômico \& Fundação IAC, 1996. 285 p. (Boletim Técnico 100).

RAIJ, B. van; QUAGGIO, J.A.; CANTARELLA, H.; FERREIRA, M.E.; LOPES. A.S.; BATAGLIA, O.C. Análise química do solo para fins de fertilidade. Campinas: Fundação Cargill, 1987. 170 p.

RIBEIRO, M.A.V. Resposta da soja e do eucalipto a fósforo em solos de diferentes texturas, níveis de densidade e de umidade. 1999. 71 f. Tese (Doutorado em Solos e Nutrição de Plantas) - Universidade Federal de Lavras, Lavras, 1999.

SECCO, D.; SILVA, V.R.; RUBIN, R.B.; JUNIOR, S.A.G.; REINERT, D.J.; REICHERT, J.M. Efeitos da compactação nos atributos físicos do solo e na produtividade da cultura do trigo, em Latosolo Vermelho-Escuro no sistema plantio direto. In: REUNIÃO BRASILEIRA DE MANEJO E CONSERVAÇÃO DO SOLO E DA ÁGUA, 13., 2000, Ilhéus. Resumos ... Viçosa - MG: Sociedade Brasileira de Ciência do Solo, 2000. 1 CD.

SIDIRAS, N.; VIEIRA, M.J. Comportamento de um Latossolo Roxo distrófico compactado pelas rodas de um trator na semeadura. Pesquisa Agropecuária Brasileira, Brasília, v.19, p.1285-93, 1984.

SIDIRAS, N.; VIEIRA, S.R.; ROTH, C.H. Determinação de algumas características físicas de um Latossolo Roxo distrófico sob plantio direto e preparo convencional. Revista Brasileira de Ciência do Solo, Campinas, v.8, p.265-8, 1984.

SILVA, V.R.; REINERT, D.J.; REICHERT, J.M. Resistência mecânica do solo à penetração influenciada pelo tráfego de uma colhedora em dois sistemas de manejo do solo. Ciência Rural, Santa Maria, v.30, n.5, p.795-801, 2000.

STIRZAKER, R.J.; PASSIOURA. J.B.; WILMS, Y. Soil structure and plant growth: impact of bulk density and biopores. Plant and Soil, Dordrecht, v.185, p.151-62, 1996.

TARDIEU, F. Growth and functioning of roots and to root systems subjected to coil compaction. Towards a system with multiple signaling. Soil \& Tillage Research, Amsterdam, v.30, n.2/4, p.217-43, 1994.

TAYLOR, H.M.; BRAR, G.S. Effect of soil compaction on root development. Soil \& Tillage Research, Amsterdam, v.19, p.111-9, 1991.

TOPP, G.C.; GALGANOW, Y.T.; WIRES, K.C. Non limiting water range (NLWR): an approach for assessing soil structure. Soil Quality Evaluation Program, Ottawa, 1994. 96p. (Technical report, 2).

TORMENA, C.A.; SILVA, A.P.; LIBARDI, P.L. Caracterização do intervalo hídrico ótimo de um Latossolo Roxo sob plantio direto. Revista Brasileira de Ciência do Solo, Viçosa, v.22, p.573-81, 1998.

WEAICH, K.; BRISTOW, K.L.; CASS, A. Preemergent shoot growth of maize under different dryin conditions. Soil Science Society of America Journal, Madison, v.56, p.1272-8, 1992. 